\title{
Da legitimidade de textos poéticos musicados como fonte para o estudo da prosódia de tempos passados do português: 0 exemplo das cantigas medievais galego-portuguesas
}

On the legitimacy of musical poetic texts as source for the study of the prosody of Portuguese ancient times: An example from medieval Galician-Portuguese cantigas

Gladis MASSINI-CAGLIARI (UNESP - Araraquara)

\section{RESUMO}

Este trabalho mostra como se podem extrair informações acerca de fenômenos fonológicos como silabação, ditongação, elisão vocálica e posição dos acentos primário e secundário, a partir da relação entre sílabas poéticas e sílabas fonéticas, tomando como exemplo uma cantiga de amigo de Martim Codax, tomada a partir da letra e da música registradas no Pergaminho Vindel.

Palavras-chave: ritmo poético; ritmo linguístico; ritmo musical; fonologia. 


\section{ABSTRACT}

This work shows how information about phonological phenomena such as syllable boundaries, diphthongization, vocalic elision and primary and secondary stress positioning can be extracted from the relation between poetic and phonetic syllables, taking as an example the music and the lyrics of one Martim Codax' cantiga de amigo.

Key-words: poetic rhythm; linguistic rhythm; musical rhythm; phonology.

\section{Introdução}

O objetivo deste trabalho é discutir uma questão metodológica importante para o estudo linguístico do português em períodos passados, mais especificamente no período medieval, quando não havia ainda tecnologia para gravação de voz e dos quais não sobraram registros orais. Intencionando contribuir para os estudos da fonologia e da prosódia do ancestral medieval do português que falamos atualmente, pretende-se mostrar como se podem extrair informações acerca de fenômenos fonológicos como silabação, ditongação, elisão vocálica, posição dos acentos primário e secundário, etc., a partir da relação entre sílabas poéticas e sílabas fonéticas, tomando como exemplo uma cantiga de amigo de Martim Codax, remanescente do cancioneiro medieval galego-português, tomada a partir do Pergaminho Vindel. Este exemplo foi escolhido dado o fato de ter sobrevivido também o testemunho de sua dimensão musical - algo bastante raro na lírica medieval galego-portuguesa profana. ${ }^{1}$ Desta forma, é possível exemplificar

1. De todos os documentos remanescentes que registram cantigas medievais profanas, apenas os Pergaminhos Vindel - fólio que contém sete cantigas de amigo de Martim Codax (musicadas), atualmente na Pierpont Morgan Library de Nova Iorque (FERREIRA, 1986) - e Sharrer - fólio que contém fragmentos de sete cantigas de amor de D. Dinis (acompanhadas de notação musical), atualmente nos Arquivos Nacionais Torre do Tombo (ANTT), Lisboa (SHARRER, 1991, 1993; FERREIRA, 2005) - contêm notações musicais. Em resumo, de toda a produção profana medieval em galego-português, conhecemos (e imperfeitamente, devido ao estado de conservação dos manuscritos) apenas 14 melodias, 6 de amigo (uma das cantigas do Pergaminho Vindel sobreviveu apenas em texto) e 7 de amor. Já a vertente religiosa da produção poética galego-portuguesa teve mais sorte: sobreviveram, com partitura, quase todas as 420 Cantigas de Santa Maria (CSM), uma 
como se podem obter informações relevantes ao estudo da prosódia do período medieval da língua também a partir da notação musical que acompanha as cantigas.

\section{Ritmo poético e ritmo linguístico}

Um pressuposto essencial à metodologia que aqui se adota é a consideração de que o fenômeno poético não é apenas um importante testemunho linguístico, mas uma forma legítima da língua que pode fornecer informações imprescindíveis sobre a estrutura linguística a partir da qual os versos se constroem, apesar de admitir certa 'licença poética" (ou seja, momentos em que acontecem subversões intencionais dos padrões linguísticos). ${ }^{2}$

coleção de cantigas em louvor da Virgem Maria, mandadas compilar pelo Rei Sábio de Castela na segunda metade do século XIII, que sobreviveram em quatro códices: o de Toledo (To), o menor e o mais antigo; o códice rico de El Escorial (T), o mais rico em conteúdo artístico, que forma um conjunto (os chamados códices das histórias) com o manuscrito de Florença (F); e o mais completo, o códice dos músicos - El Escorial (E). Deve-se observar, entretanto, que F (a exemplo do que acontece com o Cancioneiro da $A j u d a$, que registra majoritariamente cantigas de amor), contém apenas o espaço que seria utilizado posteriormente para o acréscimo da notação musical, mas não a notação propriamente dita. A respeito das Cantigas de Santa Maria e dos manuscritos em que sobreviveram, vejam-se Aita(1922), Mettmann (1986), Parkinson (1998, 2000a,b) e Fidalgo (2002), entre outros.

2. Em relação às possibilidades de desvios ao padrão fonológico da língua em textos poéticos, vejam-se Massini-Cagliari (2009) e Migliorini (2012).

O trabalho de Massini-Cagliari (2009), a partir da análise de uma canção de Chico Buarque de Holanda, baseia-se principalmente na hipótese de que proeminências musicais combinam-se prioritariamente com proeminências linguísticas. No entanto, há a possibilidade de proeminências musicais serem ocupadas por sílabas que não correspondam a proeminências linguísticas (pelo menos, não proeminências principais). Apesar de haver a possibilidade de não coincidência entre as proeminências do texto e da música, isso não pode acontecer na maior parte dos casos, tendo que se restringir a um uso estilístico marginal, porque, do contrário, não haveria a possibilidade de produção e reconhecimento de um padrão rítmico, já que os padrões de ritmo poético e musical baseiam-se na repetição de estruturas.

Migliorini (2012) analisa a ocorrência de processos fonológicos de cunho estilístico, isto é, processos considerados não esperados, a partir de um corpus constituído de Cantigas de Santa Maria, verificando os possíveis condicionamentos linguísticos envolvidos na sua realização, sobretudo no que se refere a fenômenos de sândi - crase, elisão e hiato - e paragoge. A autora conclui que o trovador não tem liberdade total para "criar" ou não formas desviantes, segundo sua vontade, para satisfazer necessidades artísticas, fato corroborado pela baixíssima margem de arbítrio de que dispunham. 
Para Allen (1973: 103), a poesia metrificada pode ser uma grande aliada no fornecimento de informações prosódicas sobre "línguas mortas":

metrical phenomena cannot be ignored, since, especially in the case of 'dead' languages, the relationship between poetry and ordinary language may provide clues to the prosodic patterning of the latter; and in any case verse form is a form of the language, albeit specialized in function, and entitled to some consideration as such.

A afirmação acima de Allen sobre como a consideração de poesia metrificada pode trazer informações importantes da prosódia de línguas mortas aplica-se também para períodos passados de línguas vivas (como o português), quando não havia ainda tecnologia para gravação de voz e dos quais não sobraram registros orais. Desta forma podem ser consideradas as cantigas medievais galego-portuguesas como fonte importante de pistas sobre o ritmo linguístico da língua falada na época, que serve de base aos versos nela compostos. A este respeito, Lehiste (1985: 153) acredita que "the suprasegmental structure of a language is crystalized [...] in the metric structure of its traditional poetry".

Para Abercrombie (1967: 98), o ritmo da fala corrente é o fundamento do verso; portanto, fala e poesia não se distinguem tipologicamente quanto ao ritmo (ABERCROMBIE, 1965: 18). Em outras palavras, para esse autor, uma língua de ritmo acentual, como o inglês, tenderá a desenvolver uma poesia que privilegiará a contagem dos acentos na metrificação; ao contrário, uma língua de ritmo silábico tenderá a dar ênfase à contagem das sílabas. Nada, entretanto, impede a combinação dos dois níveis, silábico e acentual, sobretudo em poesias suportadas por línguas de ritmo acentual. Para Abercrombie (1965), a diferença principal entre o ritmo da fala e o ritmo da poesia reside no fato de que, na poesia, o ritmo se encontra organizado de maneira a produzir - e a fazer com que o ouvinte/leitor perceba - padrões recorrentes (metros ou sílabas). ${ }^{3}$ 
Mesmo autores que consideram que a estrutura rítmico-poética é independente da estrutura rítmica no nível linguístico, como Fabb \& Halle (2008: 11), reconhecem que

Every well-formed line of metrical verse consists not only of the phonemes and syllables that determine its pronunciation, but also of what we have called a metrical grid, i.e., a pattern, which though not pronounced, determines the perception of a sequence of syllables as a line of metrical verse, rather than as an ordinary bit of prose.

O trecho citado acima comprova que, mesmo em se considerando a óbvias diferenças rítmicas entre poemas e fala comum (sendo o ritmo poético muito mais restrito e reiterativo do que o da fala), existe uma estreita relação linguística entre essas duas vertentes de uma mesma língua, que pode se constituir na pista chave quando as fontes que se tem de uma época ancestral são versificadas.

Na direção contrária de Fabb \& Halle (2008), Verluyten (1982: 257) já propunha uma correspondência entre categorias métricas (isto é, poéticas) e categorias prosódicas (ou seja, linguísticas). Neste contexto, o verso corresponderia ao enunciado, o pé métrico à palavra prosódica, e assim por diante. No entanto, embora cada categoria métrica tenha sua correspondente linguística, elas não coincidem; em outras palavras, embora a estrutura linguística seja a base da produção dos versos, as categorias métricas e prosódicas não são co-extensivas - caso contrário, a distinção entre métrica e prosódia não faria sentido. ${ }^{4}$ No mesmo caminho, Nespor e Vogel (1986) fornecem evidências a favor da correlação entre categorias prosódicas e métricas, a partir da análise da Divina Comédia, de Dante.

Embora haja uma certa discrepância entre os trabalhos citados acima quanto à forma como o ritmo linguístico serve de base ao ritmo poético, vários trabalhos apontam que é em um nível mais abstrato (o da Fonologia, e não o da Fonética) que podem ser inferidas as estruturas que regulam os versos compostos em uma determinada língua. Entre eles, podem ser citados Halle e Keyser (1971), Maling (1973), 
Youmans (1989), Prince (1989), Halle (1989), Hayes (1989) e Kiparsky (1989). ${ }^{5}$

\section{A contagem das sílabas poéticas nas cantigas medievais galego-portuguesas}

Na opinião de Michaëlis de Vasconcelos (19_ [1912-13]: 395396), a contagem das sílabas poéticas, nas cantigas medievais portuguesas, deve ser feita apenas até a última sílaba tônica. Para essa autora, a contagem das sílabas das cantigas não se distingue da contagem moderna (ou seja, a de tradição franco-portuguesa), a não ser por alguns pormenores, todos eles relativos ao encontro de vogais, quer dentro de um mesmo vocábulo, quer de vocábulo a vocábulo - Michaëlis de Vasconcelos (19_[1912-13]: 397-398):

Regra geral era então, como o é hoje: que vogal antes de vogal se absorve (no estilo épico castelhano é vogal após vogal) - a não ser que uma delas seja ditongo, ou vogal fortemente acentuada, ou que haja pausa entre as duas.

$[\ldots]$

Regra especial é: que não há elisão, quando as duas vogais consecutivas são idênticas, nem quando elas são das que costumam formar um ditongo crescente.

No 1ํo caso há fusão: em lugar de elisão, crase. De 2 vogais idênticas, nasce uma prolongada, como em averá [a] morrer [...]. - No 2o caso há sinalefa: ditongação, por ex.: na fórmula mi-aven, mi-avier [...]. Em regra é uma das semivogais i u, que precede a ou o e dá o ditongo iá iú. Apesar disso, o hiato era permitido, e é frequente nas composições arcaicas.

Sobre esse mesmo assunto, Nunes (1973, vol. I: 418) é de opinião que

Enquanto hoje costumamos contrair numa só duas vogais, sobretudo se são idênticas, a antiga métrica, em harmonia com a fala do tempo, não o fazia, tôdas as vezes que a sua junção resultava da queda das consoantes $(d, l, n)$ que primitivamente existiam entre elas.

5. Para o português, Massini-Cagliari e Cagliari (1998) consideram a poesia como "lugar" privilegiado de observação de determinados fenômenos fonológicos, sobretudo prosódicos, tanto sincrônica quanto diacronicamente. 
Lapa (1981: 230-231) é da mesma opinião:

De um modo geral, pode admitir-se que o grupo vocálico, resultante da síncope de uma consoante, era bissilábico: $a a$, $a o<a l o$; a desinência adjectiva -aes <-ales (pro-en-ça-es); os grupos provocados pela síncope do d: mer-ce-e, cre-er, ve-er, se-er; pela queda do n: ví-ir, lou$c ̧ \tilde{a}-o$. O nome de baptismo de um dos nossos talentosos jograis, Juião Bolseiro, tem rigorosamente quatro sílabas (CV 786): Ju-i-ã-o.

A respeito dos hiatos de vogais idênticas, veja-se Michaëlis de Vasconcelos (19--[1912-13]: 398-399):

Os antigos não evitavam o hiato dentro do mesmo vocábulo, se as duas vogais concorrentes procediam de outras tantas sílabas, mesmo quando eram idênticas, ou pela sua natureza podiam formar ditongo. Seer de sedere; leer de legere; veer de videre; soo de solo; cae de cadit; soedade de soledade; mão de manu; são de sano. Só os mais modernos como D. Dinis já faziam contracção métrica em seeredes veerei veeran; e às vezes mesmo gráfica, por ex.: vedes.

Para Nunes (1973, vol. I: 419), a elisão era a regra geral, no caso de encontro de vogais de vocábulos diferentes: ${ }^{6}$

Em geral, quando uma palavra acaba em vogal e a que se lhe segue assim começa também, aquela não só era absorvida por esta, como ainda hoje o fazemos na fala, mas nem mesmo se escrevia; são tantos os exemplos que é rara a trova em que o facto não se observa.

Mas quem, até hoje, melhor explicitou as regras de hiatos e elisões nos encontros vocálicos é Cunha (1961), muito embora as suas generalizações fiquem um pouco prejudicadas por contar o seu corpus com cantigas de apenas dois trovadores: Paio Gomes Charinho e João Zorro. Tira este autor - Cunha (1961: 91-92) - quatro conclusões de ordem geral e dez de ordem particular, que estão transcritas a seguir:

6. A respeito da métrica dos hiatos, também Teyssier (1987: 28 e 29), Silva Neto (1986: 412), Vasconcellos (1959: 101) e Bueno (1955: 75) são de opinião que as vogais envolvidas contam sempre como duas sílabas separadas. Além disso, Bueno (1955: 74) ressalta o fato de que, em todas as vezes em que a elisão estava indicada na escrita, ela deveria ser feita. 
De ordem geral:a) aos trovadores não repugnavam os hiatos, embora revelassem acentuada inclinação para elidir a vogal do encontro, quando átona;b) o regime da elisão estava ligado ao ritmo do verso e era contra-regrado por impedimentos fonéticos, fonêmicos e morfológicos;

c) a vogal final átona dos polissílabos perdia-se com mais freqüência que a dos monossílabos;

d) a sinalefa era aparentemente rara.

De ordem particular:

a) a vogal da preposição de só não se elidia antes de vogal quando esta era o corpo do pronome átono $o, a, o s$, as;

b) a vogal dos pronomes átonos me, lhe (ou lhi), se (ou si), xe (ou $x i$ ) sempre se elidia antes de outros fonemas vocálicos;

c) a vogal do pronome $m i$ elidia-se antes de palavras iniciadas por $e, i$ $e u$, mas ditongava-se com as vogais $a$ e $o$, quando as precedia;

d) o pronome pessoal oblíquo $o$ (a) combinava-se com as formas pronominais me, te, xe e lhe, mas, em outros casos, mantinha a sua autonomia silábica;

e) o pronome lo (la) conservava sua vogal quando precedia formas do auxiliar aver, mas podia perdê-la ou não antes de outras palavras de início vocálico;

f) não se elidia nem se yodizava a vogal do pronome e da conjunção que, bem como a das conjunções $c a$ e se;

g) a copulativa $e$ não se ditongava com uma vogal subseqüente;

h) a preposição $a$ contraía-se com o artigo el, mas hiatizava-se com outras palavras iniciadas por vogal;

i) a vogal átona final de verso não sofria elisão nem sinalefa quando seguida do pronome $o(s), a(s)$;

j) em caráter exceptivo, admitia-se a fusão silábica de vogal nasal + vogal (oral ou nasal).

\section{A cantiga escolhida para análise}

A cantiga de amigo escolhida, Ay Deus, se sab 'ora meu amigo, é a quarta das sete sobreviventes no Pergaminho Vindel, uma folha volante contendo textos de cantigas de amigo de Martim Codax acompanhadas da respectiva música (com exceção da sétima, para a qual só há a anotação do texto), provavelmente escrita em fins do século XIII ou princípios do XIV (cf. figura 1). Esta cantiga sobreviveu também, porém sem a notação musical, nos Cancioneiros da Biblioteca Nacional de Lisboa (B1281) (cf. figura 2) e da Vaticana (V887) (cf. figura 3). 

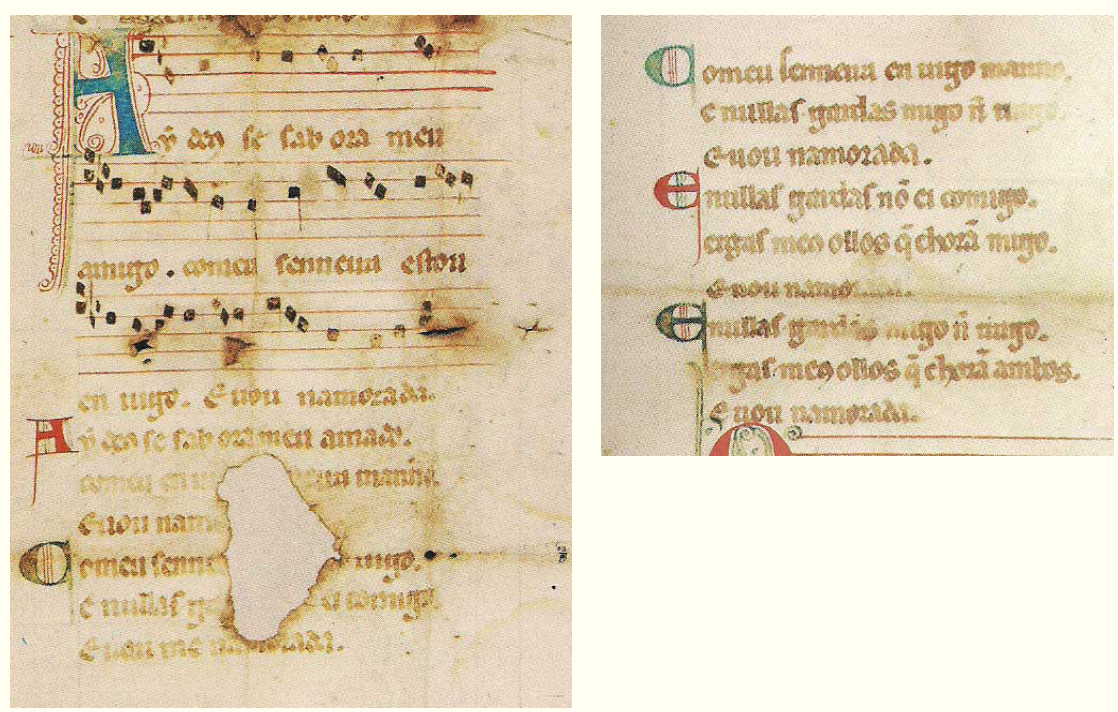

Figura 1: Cantiga Ay Deus, se sab'ora meu amigo, de Martim Codax, no Pergaminho Vindel 4 (FERREIRA, 1986, entre as páginas 74 e 75).

Figura 2: Cantiga Ay Deus, se sab'ora meu amigo, de Martim Codax, no Cancioneiro da Biblioteca Nacional de Lisboa (B1281) (MONTEAGUDO, 1998: 43).

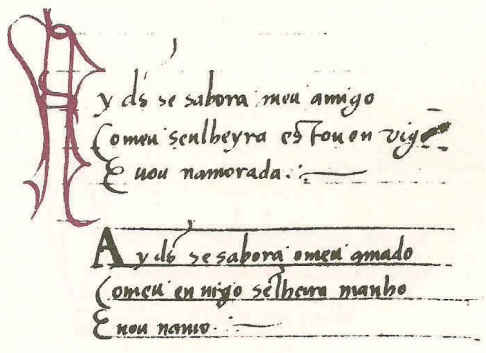

omin schein esfon vige $E$ wellhas gwandas né sé migo. Gnosna - . . . .

Comu sethein enuge manbo $E$ mothas gnardas mile ne tong. Enon: na...

E mathas guardas no' so comige Ergas meg olbg g' chora migo $\varepsilon$ mon na- -

E milow grandas, migo no trag. Eryas meg allig g cbona anto Enou na:- 


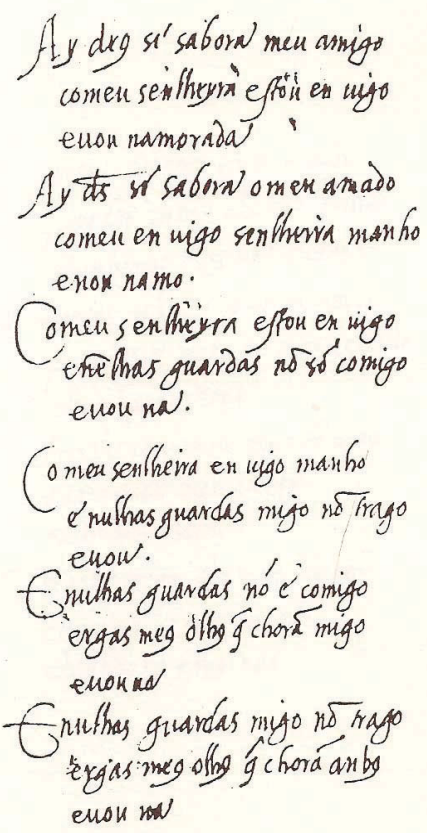

Figura 3: Cantiga Ay Deus, se sab'ora meu amigo, de Martim Codax, no Cancioneiro da Vaticana (V887) (MONTEAGUDO, 1998: 27).

Abaixo, trazemos a edição clássica desta cantiga, de Cunha (1956: 61), que é inclusive a adotada pela Lírica Profana Galego-Portuguesa (BREA, 1996: 609-610):

Ay, Deus, se sab'ora meu amigo com'eu senheyra estou en Vigo!

E vou namorada!

Ay, Deus, se sab'ora meu amado com'eu en Vigo senheyra manho!

E vou namorada!

Com'eu senheyra estou en Vigo, e nulhas gardas non ey comigo!

E vou namorada! 
Com'eu en Vigo senheyra manho, e nulhas gardas migo non trago!

E vou namorada!

E nulhas gardas non ey comigo, ergas meus olhos que choran migo!

E vou namorada!

E nulhas gardas migo non trago, ergas meus olhos que choran ambos!

E vou namorada!

A análise que faz o editor (CUNHA, 1956: 61) da estrutura métricopoética desta cantiga é a seguinte:

Cantiga de refram $6 \times(2+1)$. Estrofes paralelísticas: $a a-B$ e $c c-B$, alternadas. $\mathrm{O}$ corpo da cantiga é constituído de eneassílabos graves; o refram, de um pentassílabo, também grave. Rima breve, soante no $1^{\circ}$, no $3^{\circ}$ e no $5^{\circ}$ dístico e toante nos demais. O refram monóstico não se liga pela rima ao corpo da cantiga, embora apresente uma semiassonância com os versos dos dísticos pares.

Partindo da análise da estrutura métrico-prosódica feita por Cunha (1956), é possível obter valiosas informações sobre acerca de fenômenos fonológicos como silabação, ditongação, elisão vocálica, posição dos acentos primário e secundário da língua da época, a partir dos versos produzidos por Martim Codax.

Por exemplo, a escansão dos versos de Codax em sílabas poéticas nos traz pistas da realização das sílabas fonéticas, o que resulta na solução de dúvidas quanto à realização de encontros vocálicos em hiatos ou ditongos - exemplo (2). Neste sentido, a consideração da estrutura métrica dos versos é fundamental, uma vez que tais informações não podem ser abstraídas apenas da grafia adotada pelos trovadores, que nada esclarece quanto à realização das vogais consideradas em uma ou em duas sílabas. ${ }^{7}$

7. As barras (/) indicam limite de sílaba poética/fonética. Já o algarismo colocado entre parênteses ao final do verso indica a quantidade de sílabas poéticas por verso. A última sílaba tônica do verso, que determina até onde segue a contagem das sílabas poéticas, 


\author{
Ay,/ Deus,/ se/ sa/b'o/ra/ meu/ a/mi/go \\ co/m'eu/ se/nhey/ra/ es/tou/ en/ Vi/go! \\ $\mathrm{E} / \mathrm{vou} / \mathrm{na} / \mathrm{mo} / \mathbf{r a} / \mathrm{da}$ !
}

No exemplo acima, a partir do pressuposto de que os versos devem ser isométricos (isto é, que devem ter a mesma quantidade de sílabas poéticas) nas estrofes, pode-se dirimir dúvidas quanto à realização dos encontros vocálicos ay e $e u$, no primeiro verso da primeira estrofe, e $e u, e y$ e $o u$, no segundo verso, que, por figurarem dentro dos limites de uma única sílaba poética, devem ter sido realizados foneticamente como ditongos. Por outro lado, o encontro vocálico $a$ e, do segundo verso, deve ter sido realizado na época como um hiato, já que cada uma das vogais pertence a sílabas poéticas distintas.

Outro fenômeno fonológico que pode ser apreendido a partir da consideração da estrutura poética dos versos é a elisão. Esse processo fonológico, segundo Xavier e Mateus (1990: 140), pode ser definido como um "fenómeno de fonética sintáctica que consiste na supressão de uma vogal átona final quando a palavra seguinte começa por vogal". 8 A grafia adotada pelos cancioneiros e pergaminhos remanescentes já traz pistas do apagamento da vogal átona de final de palavras diante de outra palavra iniciada por vogal, através da supressão gráfica dessa vogal e da ausência de espaço entre as duas palavras envolvidas, que apareciam grafadas juntas. No entanto, a consideração da estrutura métrica da cantiga vem confirmar a não realização da vogal graficamente apagada, uma vez que, se fosse considerada, a estrutura isométrica dos versos seria destruída. É o que pode ser visto através do exemplo (1) acima, em todos os momentos em que o editor, Celso Cunha, optou por marcar na sua transcrição pelo apóstrofo simples. Em todos os versos em que esse apóstrofo aparece, anotando a supressão de uma vogal, a contagem das sílabas poéticas só fica correta se a elisão for efetivamente considerada.

está marcada em negrito.

8. A definição colhida em Xavier e Mateus (1990) coincide com definições anteriores desse processo, encontradas em dicionários de Linguística. A este respeito, veja-se Câmara Jr. (1973: 157), que chama atenção para o fato de a elisão também ser denominada, na literatura especializada, de "sinalefa". Como pôde ser visto anteriormente, é exatamente este o termo utilizado por Cunha (1961). Já Trask (2004: 91) define elisão apenas de modo geral, como "omissão de sons". 
A estrutura métrico-poética também revela muito sobre a posição dos acentos primários e secundários. Além de trazerem todas as informações necessárias sobre os elementos segmentais (tanto quanto os textos em prosa), a partir da observação de como o poeta conta as sílabas (poéticas) e localiza os acentos em cada verso, podem ser inferidos os padrões acentuais e rítmicos da língua na qual os poemas foram compostos. Por exemplo: da localização dos acentos poéticos, pode-se concluir a localização do acento nas palavras, ou seja, os padrões de acento lexical da língua, e, da concatenação desses acentos dentro dos limites de cada verso, os padrões rítmicos da língua em questão.

Com relação à cantiga em questão, a análise de Cunha (1956: 61) nos informa que os versos da estrofe são pentassílabos graves, isto é, versos com 5 sílabas poéticas terminados por uma palavra paroxítona, e que o do refrão é hexassílabo também grave, ou seja, versos com seis sílabas poéticas, terminados por paroxítona. Considerando esta informação, a escansão das sílabas poéticas e a existência da rima, pode-se localizar facilmente qual a sílaba tônica das palavras localizadas em final de verso, na posição de rima: comigo, amigo, Vigo, mandado, amado, vivo, sano, privado. Esta informação é extremamente relevante quando se estuda o domínio linguístico do ritmo, uma vez que as pautas acentuais das palavras da língua são cruciais para a determinação dos padrões rítmicos da língua da época.

No entanto, com relação a esta cantiga específica de Martim Codax, a estrutura métrico-poética, isoladamente, não é suficiente para nos fornecer informações acerca da posição dos demais acentos no domínio do verso. Para que isso seja possível, é necessário considerar a notação musical que acompanha a cantiga, no pergaminho Vindel.

A análise da música desta cantiga foi feita com base na edição de Ferreira (1986: 130), que, em termos de concepção musical, é bastante diferente da de Anglés (1943) para as Cantigas de Santa Maria, já que não considera que a música da época fosse organizada em unidades rítmicas do tipo "compassos", mas a partir de um ritmo que ele classifica como "rapsódico", baseado na "alternância irregular de valores breves e longos, [n]o uso de fórmulas e [n]o emprego de padrões rematados por longa" (FERREIRA, 1986: 47) - cf. figura 4. 

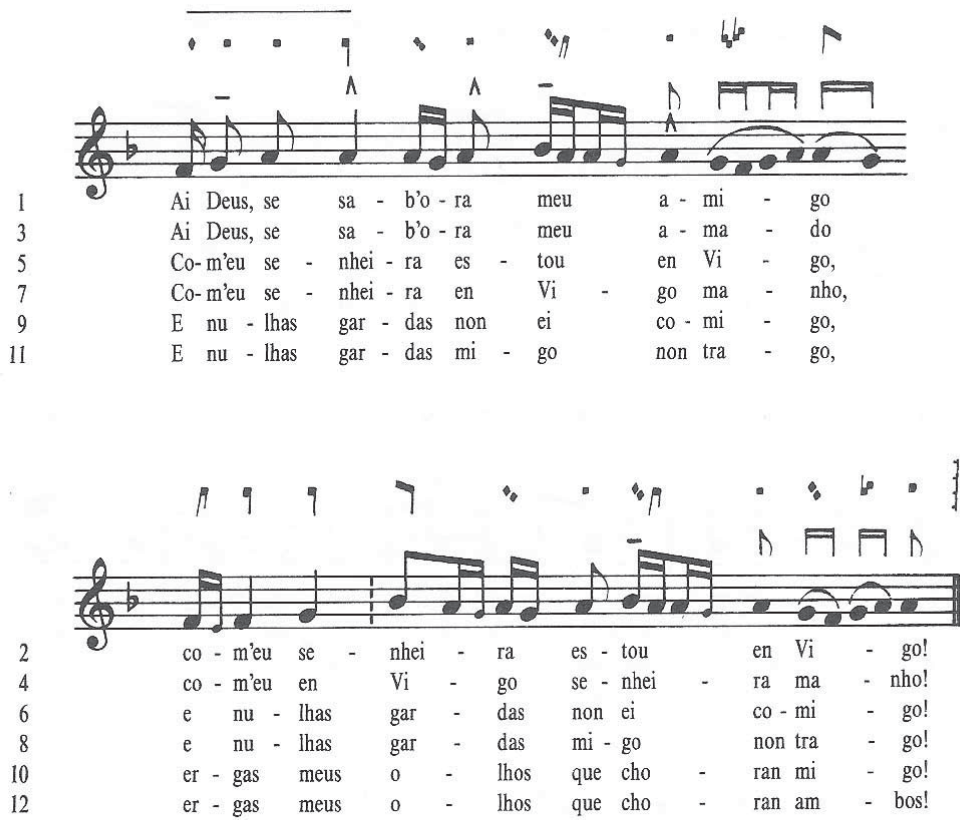

$\mathrm{R} /$.

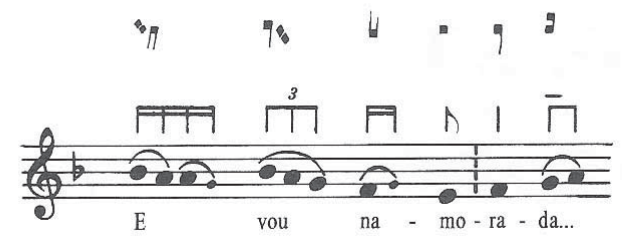

Figura 4: Edição de Ferreira (1986: 132) da cantiga Ondas do mar de Vigo, Martim Codax, Pergaminho Vindel 4

Dentro desta concepção de modelo "rimnésico" de Ferreira (1986: 39), a "acentuação musical", nas cantigas de amigo de Martim Codax, realizava-se da seguinte forma: ${ }^{9}$

9. “A respeito da longitude (ou DURAÇÃO), tem sido reconhecido e está experimentalmente provado que o alongamento relativo de um som pode criar um efeito acentual. No que se refere à altitude (ou altura), é certo, por exemplo, que uma maior ACUIDADE relativa tende a veicular acentuação. Quanto à crassitude (ou espessura) sonora, podemos entendê-la enquanto INTENSIDADE, que é o factor acentual mais em evidência, ou 
A maior duração, a maior acuidade ou a maior densidade não bastam, separadamente, para que se conclua da existência de uma acentuação; se queremos que a análise seja concludente, teremos que ver sobre que sílabas estes indicadores aparecem total ou parcialmente conjugados. Propomos neste trabalho que se considere condição necessária e suficiente para a identificação de um apoio acústico a conjugação de dois desses indicadores, desde que o terceiro factor de acentuação não dê uma indicação negativa. Assim, será considerado apoio acústico o lugar em que um elemento melódico apresente, relativamente ao anterior, a) maior duração, maior acuidade, e densidade superior ou equivalente; ou b) maior acuidade, maior densidade, e duração superior ou equivalente; ou c) maior densidade, maior duração, e acuidade superior ou equivalente. (FERREIRA, 1986: 33).

Partindo do princípio definido acima, segundo Ferreira (1986: 145), os acentos musicais, na cantiga Vindel 4, podem ser localizados nas seguintes posições:

Nos dísticos, os acentos recaem invariavelmente na $4 .^{\mathrm{a}}$ e na $9 .^{\mathrm{a}}$ sílabas, e também, mas com menor regularidade (duas excepções em doze casos), na 2. ${ }^{a}$ e na $7 .^{a}$ sílabas de cada verso; há apoio acústico invariável sobre a $7 .^{\mathrm{a}}$ sílaba [...]. Sendo os acentos na 2. ${ }^{\mathrm{a}}$ e na 3 . $^{\mathrm{a}}$ sílabas contíguos, um deles, - o menos regular - deve ser considerado secundário. Os apoios musicais confirmam a secundaridade do acento na 2. ${ }^{a}$ [...] No refrão, os acentos vocabulares recaem na 2. ${ }^{a}$ e na $5 .^{a}$ sílabas, e o acento frásico, na 5. ${ }^{\mathrm{a}}$; os apoios, definidos por via acústica, incidem na $5 .^{\mathrm{a}} \mathrm{e}$ na 6. ${ }^{\mathrm{a}}$ sílabas do verso.

Desta forma, partindo da interpretação de Ferreira (1986: 132) para a música dessa cantiga específica de Martim Codax, a tônica musical corresponde a uma tônica linguística em 100\% dos casos, mesmo em se considerando o apoio musical, excepcional, na última sílaba do refrão. Uma hipótese para a ocorrência dessa proeminência

enquanto DENSIDADE, definida como medida mélica da energia despensida no ataque de uma sílaba; pode destacar-se uma sílaba carregando-a de notas. A acentuação está também relacionada com a construção melódica: sabe-se que a reiteração, a intervalos regulares, de um som tende a produzir um efeito acentual. Tendo em conta estes factores, poderemos forjar um método que nos permita assinalar, com alguma certeza, a acentuação imanente a qualquer toada cuja curvatura e ritmo nos sejam conhecidos." (FERREIRA, 1986: 31 e 33). 
musical nesse ponto específico, em termos de correspondência com o nível linguístico, pode ser o fato de que se trata do final do constituinte prosódico, e o alongamento musical, marcado em termos de ornato, refletiria um alongamento final do último constituinte prosódico.

Ferreira (1986: 137) afirma que a construção paralelística do poema "implica a oposição em cada verso dos dísticos de uma 'base' e de uma 'coda'." A estes dois membros correspondem, nesta cantiga, dois segmentos musicais claramente diferenciados entre si: um é estável, o outro variável. Desta forma, "há uma quase total adequação entre acentuação musical e acentuação estrófica; há uma notável complementaridade entre repetição musical e variação poética, nas estrofes, e entre variação musical e repetição poética, no refrão" (FERREIRA, 1986: 173).

Temos, em conclusão, que a acentuação estrófica do poema seguido é sempre respeitada pela cantiga de seguir, provavelmente porque, como sugere a Arte de Trovar, 'doutra forma não poderia ir bem com a música'. Isso significa que a música devia, de alguma maneira, marcar os nós rítmicos do texto. A verificar-se uma tal hipótese, confirmar-se-ia a ideia de que a versificação típica das cantigas paralelísticas e de refrão galego-portuguesas é uma 'versificação puramente acentual', onde, nas palavras de Henríquez Ureña, 'as sílabas flutuam, mas a acentuação produz efeitos bem definidos, relacionados com a música ou com a origem lírica dos versos'. (FERREIRA, 1986: 173).

Outro fato a ser observado a partir da consideração da notação musical da segunda cantiga do pergaminho Vindel é a possibilidade de confirmação, a partir da música, das hipóteses de silabação, em termos de ditongação, hiatização e elisão, feitas a partir da estrutura métricopoética da cantiga. Como se pode ver a partir da figura 5, abaixo, que focaliza a notação musical sobre a qual se distribui a primeira estrofe, seguindo os padrões da época, aos ditongos, marcados com círculos, corresponde apenas uma nota ou grupo de notas que designa um ornato; já aos hiatos, marcados com retângulos, correspondem duas figuras musicais, que necessitam de duas sílabas para seu preenchimento. A notação musical confirma também a realização das elisões, marcadas em retângulos descontínuos, uma vez que não existem figuras musicais correspondentes à vogal apagada, o que indica que ela não se realizava foneticamente. 

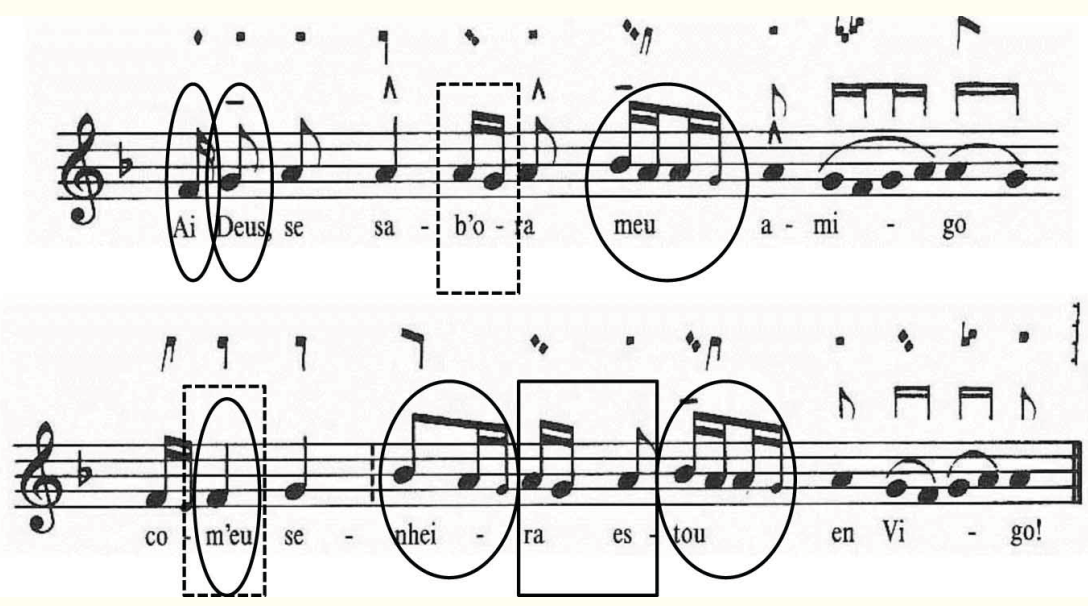

Figura 5: Edição de Ferreira (1986: 132) da cantiga Ondas do mar de Vigo, Martim Codax, Pergaminho Vindel 4: primeira estrofe.

\section{Conclusão}

Através da exemplificação realizada a partir da consideração da segunda cantiga de Martim Codax, Ay Deus, se sab'ora meu amigo, presente no pergaminho Vindel, foi possível mostrar como informações acerca de fenômenos fonológicos (silabação, ditongação, elisão vocálica e posição dos acentos primário e secundário) podem ser extraídas da relação entre sílabas poéticas e sílabas fonéticas. Além disso, também foi possível mostrar como informações relevantes ao estudo da prosódia do período medieval da língua podem ser extraídas da notação musical que acompanha as cantigas. Assim sendo, esperamos ter comprovado a adequação e a eficácia da metodologia aqui apresentada e ter mostrado que, mesmo quando há exceções (quase sempre interpretadas como "usos estilísticos" - como, por exemplo, o apoio acústico da música sobre a sílaba átona final do refrão), estas não atrapalham a abstração de elementos prosódicos da língua a partir da poesia que nela se alicerça. Pelo contrário, as exceções, por serem compreensíveis e explicáveis, são também fonte importante de formulação de hipóteses sobre a fonologia da língua da época.

Recebido em março 2013

Aprovado em março 2014 E-mail: gladismac@gmail.com 


\section{Referências bibliográficas}

Abercrombie, D. 1965. Studies in Phonetics and Linguistics. Oxford: Oxford University Press.

. 1967. Elements of General Phonetics. Edinburgh: Edinburgh University Press.

Aita, N. 1922. O Códice florentino das cantigas do Rey Affonso, o sábio. Rio de Janeiro: Litho-Typo Fluminense.

Allen, W. S. 1973. Accent and Rhythm. Prosodic Features of Latin and Greek: a Study in Theory and Reconstruction. Cambridge: Cambridge University Press.

Anglés, H. 1943. La Música de las Cantigas de Santa María del Rey Alfonso el Sabio. - Facsímil, transcripción y estudio crítico por Higinio Anglés. Barcelona: Diputación Provincial de Barcelona; Biblioteca Central; Publicaciones de la Sección de Música, 1. Volume II - Transcripción Musical.

Brea, M. (coord.) 1996. Lírica profana galego-portuguesa. Santiago de Compostela: Centro de Investigacións Lingüísticas e Literarias Ramón Piñeiro; Xunta de Galicia.

Bueno, F. da S. 1955. A formação histórica da língua portuguesa. Rio de Janeiro: Livraria Acadêmica.

CAgliari, L. C. 1984. Análise fonética do ritmo em poesia. EPA, Campinas, n.3, p. 67-96.

CÂMARA JR., J. M. [1973] Dicionário de filologia e gramática referente à língua portuguesa. 5. ed. Rio de Janeiro: J. Ozon Editor.

Cunha, C. F. 1956. O cancioneiro de Martin Codax. Rio de Janeiro: Imprensa Nacional.

. 1961. Estudos de poética trovadoresca: versificação e ecdótica. Rio de Janeiro: MEC/Instituto Nacional do Livro.

FABB, N. \& HALLE, M. 2008. Meter in Poetry. A new theory. Cambridge: Cambridge University Press.

FerreIRA, M. P. 1986. O som de Martin Codax: sobre a dimensão musical da lírica galego-portuguesa (séculos XII-XIV). Lisboa: UNYSIS, Imprensa Nacional - Casa da Moeda.

2005. Cantus coronatus. 7 Cantigas d'El-Rei Dom Dinis by King Dinis of Portugal. Kassel: Reichenberger.

Fidalgo, E. 2002. As Cantigas de Santa Maria. Vigo: Edicións Xerais de Galicia.

HaLle, M. 1989. Addendum to Prince's "Metrical Forms". In: KIPARSKY, P. \& YOUMANS, G. (Ed.). Phonetics and Phonology. New York: Academic Press. p. 81-86. Volume 1: Rhythm and Meter. 
. \& KEYSER, S. J. 1971. English Stress: its form, its growth, and its role in verse. New York: Harper \& Row.

HAYes, B. 1989. The prosodic hierarchy in meter. In: KIPARSKY, P. \& YOUMANS, G. (Ed.). Phonetics and Phonology. New York: Academic Press. p. 201-260. Volume 1: Rhythm and Meter.

KIPARSKY, P. 1989. Sprung Rhythm. In: KIPARSKY, P. \& YOUMANS, G. (Ed.). Phonetics and Phonology. New York: Academic Press. p. 305-340. Volume 1: Rhythm and Meter.

LAPA, M. R. 1981. Lições de Literatura Portuguesa: Época Medieval. 10. ed. revista pelo autor. Coimbra: Ed. Coimbra.

LeHISTE, I. 1985. Rhythm in poetry, rhythm of prose. In FROMKIN, V. A. Phonetic Linguistics: Essays in honor of Peter Ladefoged. Orlando: Academic. p. 145-155.

Maling, J. M. 1973. The Theory of Classical Arabic Metrics. Ph.D. Thesis (Linguistics)- Department of Linguistics and Philosophy, Massachusetts Institute of Technology, Cambridge, MA. Distributed by: MIT Working Papers in Linguistics.

Massini-Cagliari, G. 2009. Fonologia Histórica: estudando o ritmo lingüístico a partir de uma interface Lingüística-Música. In Hora, Dermeval da (org.) Anais - VI Congresso Internacional da Abralin. João Pessoa: Idéia. p. 1683- 1692.

. \& CAGLIARI, L. C. 1998. De sons de poetas OU Estudando fonologia através da poesia. Revista da ANPOLL, São Paulo, n. 5, p. 77-105, jul./dez.

Mettmann, W. (Ed.). 1986. Cantigas de Santa María (cantigas 1 a 100): Alfonso X, el Sabio. Madrid: Castalia.

MichaëLIs de VAsConcelos, C. Lições de filologia portuguesa (segundo as preleções feitas aos cursos de 1911/12 e de 1912/13) seguidas das lições práticas de português arcaico. Rio de Janeiro: Martins Fontes, [19--]. Referido como 1912-1913.

Migliorini, L. M. Q. 2012. De versos e trovas: análise de aspectos fonoestilísticos do Português Medieval por meio das Cantigas de Santa Maria. Tese de Doutorado (Linguística e Língua Portuguesa). Monteagudo, H. 1998. Martín Codax - cantigas. 2a edición. Vigo: Galáxia.

Nespor, M. \& VOGEL, I. 1986. Prosodic Phonology. Dordrecht: Foris Publications.

Nunes, J. J. 1973. Cantigas d'amigo dos trovadores galego-portugueses. Lisboa: Centro do Livro Brasileiro. [1. ed. 1926/1929]

Parkinson, S. 1998a. As Cantigas de Santa Maria: estado das cuestións textuais. Anuario de estudios literarios galegos, Vigo, p. 179-205. 
2000a. Layout and Structure of the Toledo Manuscript of the Cantigas de Santa Maria. In: PARKINSON, S. (Ed.). Cobras e Son: Papers on the Text Music and Manuscripts of the 'Cantigas de Santa Maria'. Oxford: Legenda, University of Oxford. p. 133-153.

2000b. Layout in the Códices ricos of the Cantigas de Santa Maria. Hispanic Research Journal, Leeds, v. 1, n. 3, p. 243-274, October.

Prince, A. S. 1989. Metrical Forms. In: KIPARSKY, P. \& YOUMANS, G. (Ed.). Phonetics and Phonology. New York: Academic Press. p. 45-80. Volume 1: Rhythm and Meter.

Sharrer, H. L. 1991. Fragmentos de sete cantigas d'amor de D. Dinis, musicadas - uma descoberta. In: CONGRESSO DAASSOCIAÇÃO HISPÂNICA DE LITERATURA MEDIEVAL, IV., 1991, Lisboa, Actas... Lisboa: Edições Cosmos. v. I. Sessões Plenárias. p. 13-29. . 1993. Pergaminho Sharrer. In: LANCIANI, G. \& TAVANI, G. (Org.). Dicionário da literatura medieval galega e portuguesa. Lisboa: Caminho. p. 534-536.

Silva Neto, S. 1986. História da língua portuguesa. 4. ed. Rio de Janeiro: Presença/INL. [1. ed. 1957]

Teyssier, P. 1987. História da língua portuguesa. 3. ed. portuguesa. Lisboa: Sá da Costa.

TRASK, R. L. 2004. Dicionário de linguagem e lingüística. Tradução e adaptação de Rodolfo Ilari. São Paulo: Contexto.

VAsConcellos, J. L. 1959. Lições de filologia portuguesa. 3. ed. Rio de Janeiro: Livros de Portugal.

VerLuYten, S. P. M. 1981. Recherches sur la prosodie et la métrique du Français. Thèse de Doctorat (Linguistique)-Universitaire Instelling Antwerpen, Wilrijk.

Youmans, G. 1989, Introduction: Rhythm and Meter. In: KIPARSKY, P. \& YOUMANS, G. (Ed.). Phonetics and Phonology. New York: Academic Press. p. 1-14. Volume 1: Rhythm and Meter.

XAVIER, M. F. \& MATEUS, M. H. M. (Org.). 1990. Dicionário de termos lingüísticos. Lisboa: Cosmos. v. 1. 